\title{
Pré-natal do parceiro: concepções, práticas e dificuldades enfrentadas por enfermeiros
}

\author{
Prenatal care prenatal care for the partner: conceptions, practices and difficulties faced by nurses \\ Atención prenatal de la pareja: concepciones, prácticas y dificultades que enfrentan las enfermeras
}

Recebido: 07/05/2021 | Revisado: 13/05/2021 | Aceito: 18/05/2021 | Publicado: 06/06/2021

\author{
Natália Gentil Lima \\ ORCID: https://orcid.org/0000-0002-8721-1454 \\ Universidade do Estado de Mato Grosso, Brasil \\ E-mail: natalia.gentil@unemat.br \\ Fernanda Sobrinho de Oliveira \\ ORCID: https://orcid.org/0000-0001-7866-1130 \\ Universidade do Estado de Mato Grosso, Brasil \\ E-mail: fernandasobrinhooliveira@ hotmail.com \\ Aireno de Sousa Silva \\ ORCID: https://orcid.org/0000-0002-4404-705X \\ Universidade do Estado de Mato Grosso, Brasil \\ E-mail: aireno.silva@unemat.com.br \\ Renata Tomazelli Ferreira \\ ORCID: https://orcid.org/0000-0002-7283-478X \\ Universidade do Estado de Mato Grosso, Brasil \\ E-mail: renatatomferrerira@gmail.com \\ Antonia Dinágila do Nascimento Ribeiro \\ ORCID:https://orcid.org/0000-0001-7852-9199 \\ Universidade do Estado de Mato Grosso, Brasil \\ E-mail: dinagila.ribeiro@unemat.br \\ Grasiela Cristina Silva Botelho Silvestre \\ ORCID:https://orcid.org/0000-0001-5367-4648 \\ Universidade do Estado de Mato Grosso, Brasil \\ E-mail: enf.grasielabotelho@gmail.com \\ Roseany Patricia Silva Rocha \\ ORCID:https://orcid.org/0000-0002-2295-5321 \\ Universidade do Estado de Mato Grosso, Brasil \\ E-mail: roseanyrocha1@gmail.com
}

\begin{abstract}
Resumo
Objetivo: investigar como os enfermeiros das Unidades Básicas de Saúde (UBS) do Município de Cáceres-MT realizam o pré-natal do parceiro, quais suas concepções e os principais desafios encontrados no atendimento ao homem. Método: trata-se de um estudo a campo de natureza descritiva, com abordagem qualitativa, realizado em julho de 2019, com os profissionais enfermeiros que atuam nas Unidades Básicas de Saúde (UBS) do município de Cáceres-MT. Para análise dos dados foi utilizado a técnica de análise de conteúdo, descrita por Minayo (2013). Resultados: dos onze enfermeiros entrevistados apenas quatro afirmaram que realizam o pré-natal do parceiro, foi evidenciado as seguintes ações/procedimentos: solicitação de exames, vacinação e orientações. Conclusão: constatou-se que a realização do pré-natal do parceiro ainda é uma estratégia pouco consolidada nos serviços de saúde do município de Cáceres-MT. Os profissionais possuem conhecimento sobre o pré-natal do parceiro e reconhecem os benefícios dessa estratégia, entretanto encontram dificuldades para efetivá-la.
\end{abstract}

Palavras-chave: Pré-natal; Atenção básica; Paternidade; Saúde do homem; Cuidado pré-natal.

\begin{abstract}
Objective: to investigate how nurses from Basic Health Units (UBS) in the municipality of Cáceres-MT perform prenatal care for their partner, what their conceptions are and the main challenges encountered in caring for men. Method: this is a descriptive field study with a qualitative approach, carried out in July 2019, with professional nurses who work in Basic Health Units (UBS) in the municipality of Cáceres-MT. For data analysis, the content analysis technique, described by Minayo (2013), was used. Results: of the eleven nurses interviewed, only four stated that they perform the partner's prenatal care, the following actions / procedures were evidenced: request for exams, vaccination and guidance. Conclusion: it was found that the performance of the partner's prenatal care is still a poorly consolidated strategy in the health services of the municipality of Cáceres-MT. Professionals have knowledge about the partner's prenatal care and recognize the benefits of this strategy, however they find it difficult to carry it out.
\end{abstract}


Keywords: Prenatal care; Basic care; Paternity; Men's health; Prenatal care.

\begin{abstract}
Resumen
Objetivo: investigar cómo las enfermeras de las Unidades Básicas de Salud (UBS) del municipio de Cáceres-MT realizan la atención prenatal a su pareja, cuáles son sus concepciones y los principales desafíos que se encuentran en el cuidado del hombre. Método: se trata de un estudio descriptivo de campo con abordaje cualitativo, realizado en julio de 2019, con profesionales de enfermería que laboran en Unidades Básicas de Salud (UBS) del municipio de Cáceres-MT. Para el análisis de los datos se utilizó la técnica de análisis de contenido, descrita por Minayo (2013). Resultados: de las once enfermeras entrevistadas, solo cuatro manifestaron que realizan la atención prenatal de la pareja, se evidenciaron las siguientes acciones / procedimientos: solicitud de exámenes, vacunación y orientación. Conclusión: se encontró que la realización de la atención prenatal de la pareja es aún una estrategia poco consolidada en los servicios de salud del municipio de Cáceres-MT. Los profesionales tienen conocimiento sobre la atención prenatal de la pareja y reconocen los beneficios de esta estrategia, sin embargo les resulta difícil implementarla.
\end{abstract}

Palabras clave: Atención prenatal; Cuidado básico; Paternidad; Salud de los hombres; Cuidado prenatal.

\title{
1. Introdução
}

O pré-natal do parceiro é uma estratégia inovadora, instituída pelo Ministério da Saúde, em 2016, que busca contextualizar a importância do envolvimento consciente e ativo de homens em todas as ações voltadas ao planejamento reprodutivo e, ao mesmo tempo, contribuir para a ampliação e a melhoria do acesso e acolhimento desta população aos serviços de saúde, com enfoque na Atenção Básica (Brasil, 2016; Almeida et al., 2021).

Historicamente, tanto o planejamento reprodutivo quanto às ações em saúde voltadas ao momento da gestação, parto e puerpério foram pensadas e direcionadas às mulheres e às gestantes, enfocando o binômio mãe-criança. No entanto, nos últimos anos, não só no Brasil, mas em outros países também, tem se discutido sobre a importância do envolvimento ativo do pai/parceiro em todas as fases da gestação (Brasil, 2016; Mendes \& Santos, 2019).

A Política Nacional de Atenção Integral à Saúde do Homem (PNAISH), instituída em 2009, tem como objetivo ampliar o acesso e o acolhimento dos homens aos serviços e programas de saúde através da inclusão do tema da paternidade e cuidado, por meio do Pré-Natal do Parceiro nos debates e nas ações voltadas para o planejamento reprodutivo como uma estratégia essencial para qualificar a atenção à gestação, ao parto e ao nascimento (Brasil, 2009).

Dessa forma, o Pré-natal do parceiro constitui-se em uma porta de entrada para os homens nos serviços de saúde, aproveitando sua presença nas consultas de pré-natal para ofertar exames de rotina e atividades educativas, buscando a integralidade no cuidado a esta população. Trata-se de um momento oportuno que pode transformar as construções sociais de gênero que prejudicam a aproximação dos homens com os serviços de saúde, favorecendo a paternidade ativa através do compartilhamento de responsabilidade desde a gestação até os cuidados com a criança (Brasil, 2016; Cofen, 2017).

Apesar de todas as iniciativas governamentais, alguns estudos demonstram que a participação do pai/parceiro ainda é rara devido a vários aspectos, como questões de gênero, o horário de funcionamento da UBS, a falta de ações voltadas aos homens, e a falta de incentivo da própria mulher e da equipe de saúde à participação do parceiro (Cardoso et al., 2018; Caldeira et al., 2017; Moreira, Fontes \& Barboza, 2014).

Em relação ao papel do enfermeiro no pré-natal, conforme a Lei no 7.498/86 do Exercício da enfermagem, este pode acompanhar inteiramente o pré-natal de baixo risco na rede básica de saúde, onde por meio da consulta de enfermagem deve propiciar condições para a promoção da saúde e melhoria da qualidade de vida da gestante e de seu parceiro mediante uma abordagem contextualizada e participativa (Brasil, 2012).

Frente a estes aspectos, esta pesquisa teve como objetivo investigar como os enfermeiros das Unidades Básicas de Saúde (UBS) do Município de Cáceres-MT realizam o pré-natal do parceiro, quais suas concepções e os principais desafios encontrados no atendimento ao homem. 


\section{Metodologia}

Trata-se de um estudo a campo de natureza descritiva, com abordagem qualitativa, realizado nas Unidades Básicas de Saúde no município de Cáceres-MT, em julho de 2019. A população do estudo foi composta por onze enfermeiros.

A coleta de dados foi realizada por meio de entrevista com um roteiro semiestruturado, gravada em equipamento de áudio, e os dados foram transcritos e analisados segundo a técnica de análise de conteúdo, proposta por Minayo, que consiste nas seguintes etapas: decompor o material a ser analisado em partes, distribuir as partes em categorias, fazer uma descrição do resultado da categorização, fazer inferências dos resultados e interpretar os resultados obtidos com auxílio da fundamentação teórica adotada (Minayo, 2013).

O projeto de pesquisa foi aprovado pelo Comitê de Ética e Pesquisa da Universidade do Estado de Mato Grosso (UNEMAT) sob o parecer $\mathrm{n}^{\mathbf{0}}$ 3.323.088. O início da pesquisa ocorreu após a explicação e esclarecimento de todas as dúvidas do entrevistado e assinatura do Termo de consentimento livre e esclarecido (TCLE). Os entrevistados tiveram seus nomes substituídos pela palavra "enfermeiro" seguido de um número. Foram cumpridos os princípios éticos estabelecidos na Resolução 466/2012 do Conselho Nacional de Saúde.

\section{Resultados e Discussão}

A partir das entrevistas, usando a técnica de análise de conteúdo, os depoimentos foram organizados em quatro grandes categorias: Concepção sobre o pré-natal do parceiro, O pré-natal do parceiro realizado por enfermeiros das UBS, Fatores que dificultam a realização do Pré-natal do parceiro e Saúde do Homem.

\section{Categoria 1: Concepção sobre o pré-natal do parceiro}

A compreensão dos enfermeiros em relação ao Pré-natal do parceiro está basicamente relacionada a três aspectos principais conforme descritos abaixo:

\section{Estratégia para realização de exames}

Os enfermeiros demonstraram em suas falas o entendimento de que o pré-natal do parceiro é um momento para realização de exames, conforme trechos das falas:

Então assim, acaba que a gente realizou esse pré-natal do parceiro porque foi solicitado os exames [...]. (Enfermeiro 6)

O pré-natal do parceiro, ele envolve o companheiro da gestante no seu pré-natal e ele envolve uma série de orientações, além de exames complementares. (Enfermeiro 7)

O pré-natal do parceiro geralmente, ele é mais focado nas questões de DSTs e de incompatibilidade sanguínea. (Enfermeiro 8)

Foi evidenciado nas falas dos entrevistados que estes associam o Pré-natal do parceiro à realização de exames e testes rápidos para Infecções Sexualmente Transmissíveis (IST). É importante destacar a realização dos testes rápidos, pois um dos principais problemas relacionados ao controle dessas doenças durante a gravidez é a abordagem do parceiro e a tentativa de convencê-los da necessidade diagnóstica e de adesão ao tratamento (Duarte, 2017). 
Dessa forma, o Ministério da Saúde reforça sobre a preparação da equipe/serviço para acolher estes usuários, sendo essencial conhecer as principais vulnerabilidades e as necessidades particulares, suas características e estilos de vida e desenvolver uma abordagem sobre os riscos, respeitando as suas especificidades (Brasil, 2016).

A ocorrência das ISTs durante a gravidez representa risco aumentado de morbidade e mortalidade para o feto e o neonato em virtude da transmissão vertical, portanto o pré-natal pode se configurar com uma importante estratégia para a redução dessa transmissão, por meio da realização dos testes rápidos e orientações repassadas à gestante e ao parceiro de forma simultânea (Silva et al., 2020).

A realização de exames e testes rápidos é uma das ações preconizadas pelo Ministério da Saúde, porém vale ressaltar que o Pré-natal do parceiro não se limita a somente esta ação em específico, é uma estratégica que abrange vários cuidados a saúde do homem.

\section{Programa do Ministério da Saúde}

Durante as entrevistas, foi mencionado pelos enfermeiros, várias vezes, o termo "Ministério da Saúde", indicando, portanto, o reconhecimento do pré-natal do parceiro como uma medida ou programa instituído pelo governo federal.

Sobre o pré-natal do parceiro ele é uma das medidas, um dos programas que o Ministério da Saúde adota. (Enfermeiro 1)

O pré-natal do parceiro, ele foi instituído pelo Ministério da Saúde, né? Numa cartilha, né? Saiu uma cartilha no ano de dois mil e dezesseis, eu acho, para os profissionais começar a trabalhar. (Enfermeiro 5)

Quando o Ministério da Saúde introduziu o pré-natal do parceiro, veio uma nota, para as unidades, né? Informando sobre essa nova iniciativa. (Enfermeiro 10)

Foi evidenciado, pelas falas dos entrevistados, que reconhecem o pré-natal do parceiro como iniciativa do Ministério da Saúde, porém quando questionados se conheciam o "Guia do Pré-Natal do Parceiro para os Profissionais de Saúde" publicado em 2016, a maioria afirmou desconhecimento. Este desconhecimento pode estar atrelado ao fato de que os enfermeiros não receberam nenhuma capacitação sobre o tema.

Dessa forma, ressaltamos a importância da Educação Permanente em Saúde (EPS) nesse contexto, pois possibilita transformar as práticas nos serviços de saúde a partir da reflexão sobre o processo de trabalho. A EPS é uma estratégia profícua de aperfeiçoamento profissional e precisa ser entendida pelos gestores como parte do trabalho em saúde (Brasil, 2018).

\section{Oportunidade para envolvimento do homem na gestação.}

Os enfermeiros reconhecem o pré-natal do parceiro como um momento importante para envolver o homem na gestação e citaram como benefícios desse envolvimento: o reconhecimento do papel do parceiro como cuidador, o apoio e valorização da mulher, o aumento do vínculo e o conhecimento dos próprios direitos.

Que o pré-natal perca um pouco o foco só, na verdade, na gestação, mas que comece abrangendo principalmente o papel de outros cuidadores também como, por exemplo, o pai. (Enfermeiro 1) 
É importante porque, o homem ele se sente mais participante, mais ativo na vida da gestante [...] ele também se informa sobre os direitos dele também. Sobre o direito de assistir o parto, de permanecer na sala do alojamento conjunto, então ele sabe todos os direitos dele também aqui na consulta de pré-natal. (Enfermeiro 7)

Gera um comprometimento maior, um vínculo maior [...]. (Enfermeiro 2)

Melhora até a questão emocional da gestante que fica numa situação muito fragilizada [...]. (Enfermeiro 8)

Os enfermeiros 1 e 7 destacam em suas falas a importância do envolvimento do parceiro no pré-natal para que se sinta parte deste processo. Essa participação contribui para que ele se sinta valorizado como pai, tenha oportunidade de receber informações e se sensibilize com as mudanças que ocorrem com a sua parceira e com a criança, como por exemplo por meio da ultrassonografia, que permite ao pai ter a imagem da criança na sua mente, dando a sensação de fazer parte deste processo (Branco et al., 2009; Matos \& Magalhães, 2017).

A participação do pai contribui para o desenvolvimento de uma gestação mais saudável, maior igualdade de gênero, maior confiança da gestante, o que contribuirá para que a criança tenha um desenvolvimento saudável (Sousa, et al., 2021).

Além disso, estudos afirmam que os pais que estão envolvidos no cuidado de seus bebês têm maior possibilidade de desenvolver um vínculo emocional com ele e contribui para o desenvolvimento de habilidades de cuidado (Branco et al., 2009; Benczik, 2011). Corroborando com esta ideia, uma pesquisa realizada com puérperas acerca do apoio do companheiro durante a gestação e parto, evidenciou que a experiência de ser acompanhada pelo parceiro foi considerada positiva pela maioria das puérperas, pois favoreceu o fortalecimento do vínculo entre o casal e com o recém-nascido (Holanda et al., 2018).

Outro estudo demonstrou que a experiência vivida no pré-natal e nascimento trouxe a possibilidade da ressignificação da masculinidade do ser pai, rompendo com as crenças sociais e estimulou a percepção do homem de que ele não é apenas um suporte para a mãe e o bebê, ele faz parte de todo o processo (Braide et al., 2019).

De acordo com o enfermeiro 8, o parceiro pode oferecer suporte emocional à mulher, pois a gestação é um momento de transformações em seu organismo que podem interferir no dia-a-dia, incluindo sexualidade, prazer e a relação a dois, além de algumas serem desconfortáveis e provocar medo, portanto, o parceiro se torna importante para ajudar a mulher a enfrentar essas situações (Camacho, Vargens \& Progianti, 2010).

Alguns estudos evidenciaram que as gestantes que tiveram a presença de acompanhantes se sentiram mais seguras durante o parto, houve redução do uso de medicações para alívio da dor, da duração do trabalho de parto e do número de cesáreas e a redução dos casos de depressão pós-parto (Brasil, 2012).

Outro aspecto importante, que foi citado pelo enfermeiro 7, é sobre os direitos do parceiro. Uma das recomendações do Ministério da Saúde, durante o pré-natal do parceiro, é justamente essa, a de informar sobre os direitos, que estão pautados na Lei Federal $\mathrm{n}^{\mathrm{o}}$ 11.108/05 que estabelece que a mulher tem direito a um acompanhante de sua livre escolha durante todo o período de trabalho de parto, parto e pós-parto imediato e na Lei 13.257/2016 que estabelece o direito à licença paternidade.

É importante destacar que apenas um enfermeiro (enfermeiro 10) mencionou como um dos benefícios do envolvimento do parceiro na gestação, os cuidados com a própria saúde.

Até cuidar da saúde dele, muitas vezes naquele momento do pré-natal, que ele não se preocupa em marcar uma consulta para ele, é o momento da gente está avaliando, a gente está conversando, tirando as dúvidas. (Enfermeiro 10) 
O profissional da saúde, especialmente o enfermeiro, deve estimular o envolvimento do parceiro nas diversas atividades que podem ser desenvolvidas na Atenção Básica, tais como as de prevenção a doenças e promoção à saúde, tanto individual quanto coletivamente, despertando a responsabilidade e senso de compromisso com a saúde/doença, criando estratégias para minimizar os riscos encontrados, respeitando sua autonomia e liberdade (Santana \& Gonçalves, 2020).

\section{Categoria 2: ações/procedimentos desenvolvidos durante o pré-natal do parceiro}

Em relação a realização do pré-natal do parceiro nas UBS do município de Cáceres-MT, dos onze entrevistados apenas quatro afirmaram que realizam o pré-natal do parceiro. A partir dos depoimentos foram evidenciadas as seguintes ações/procedimentos: solicitação de exames, vacinação e orientações.

Sim. Uma consulta de enfermagem. Solicitações dos exames, encaminhamento para a vacinação, para atualização do cartão e o retorno também com o médico e a participação dele durante as consultas de pré-natal. (Enfermeiro 4)

Sim, realizo. Então, a gente realiza orientações, solicita alguns exames, verifica também a caderneta de vacinação dele, tem também os testes rápidos. (Enfermeiro 5)

A gente realiza junto com a gestante, nas orientações da gestante, no pré-natal da gestante, a gente já faz as orientações para o parceiro, tanto em relação ao estado da gestante, enquanto a gente aproveita para tirar as dúvidas os parceiros sobre várias perguntas que eles trazem, sobre humor da gestante, sinais de risco ou às vezes sobre ele mesmo. (Enfermeiro 10)

Um enfermeiro mencionou a realização do acolhimento do parceiro e o envolvimento dele nos procedimentos realizados com a mulher, como por exemplo a ausculta do BCF:

A gente faz o acolhimento desse parceiro, esse acolhimento envolve tanto a escuta das suas dúvidas, a gente também orienta, a gente no caso eu. Oriento que ele pode entrar na minha sala junto com a gestante e quando eu vou auscultar por exemplo o BCF, eu deixo ele também auscultar o BCF, para ele participar e não só auscultar o BCF, mas ele coloca juntamente o aparelho para ele achar também o coraçãozinho do filho[...]. (Enfermeiro 7)

As ações citadas pelos enfermeiros estão contempladas no Guia do Pré-natal do parceiro do Ministério da Saúde, que as divide em cinco (5) passos: acolhimento do parceiro na UBS, solicitação de exames e testes rápidos, vacinação, orientações sobre temas relacionados à saúde do homem e orientações sobre a relevância da participação e envolvimento do parceiro em todos os momentos da gestação e pós-parto.

Considerando o que é orientado pelo Ministério da Saúde e o que foi citado pelos enfermeiros, percebe-se que estes realizam parcialmente as ações/procedimentos preconizados. Ainda se faz necessário maior envolvimento do parceiro nas consultas, e principalmente a realização de palestras e/ou rodas de conversas com temas voltados a saúde do homem $\left(4^{\circ}\right.$ passo), pois não foi mencionado por nenhum enfermeiro.

A realização de práticas educativas em grupo de gestantes ou casais são essenciais para que o parceiro possa compreender o exercício da paternidade já durante a gestação, através da aprendizagem quanto aos cuidados com a mãe e o bebê, o parto e pós-parto e incentivo à prática de aleitamento materno (Cavalcanti \& Holanda, 2019). 
Os grupos são desenvolvidos com a finalidade de complementar o atendimento realizado nas consultas e através das rodas de conversa é possível estabelecer uma participação coletiva e dialogar com os sujeitos que se expressam e escutam seus pares por meio do exercício reflexivo (Lima et al., 2019).

Além dos temas voltados a paternidade, o Ministério da Saúde orienta a abordagem de outros assuntos relativos à saúde do homem, como a prática de atividades físicas regulares, alimentação balanceada e saudável, a Política Nacional de Atenção Integral à Saúde do Homem, gênero, socialização masculina e impactos para a vida de homens, mulheres e crianças; sexualidade, direitos sexuais e direitos reprodutivos; prevenção de acidentes e de violência entre a população masculina.

Dessa forma, fica evidente a importância da educação em saúde, pois permite a transformação dos usuários, a obtenção de novos hábitos e comportamentos em saúde, aumentando sua capacidade de compreensão sobre o processo saúde/doença (Climaco et al., 2020).

Quando os profissionais foram questionados sobre a estratégia utilizada para conseguir adesão dos parceiros nas consultas, de forma unânime os participantes responderam que a única estratégia utilizada é a "orientação a gestante".

No âmbito da atenção básica, a orientação é uma estratégia fundamental para a prevenção e promoção à saúde, porém em alguns casos pode-se mostrar pouco efetiva sendo necessário a construção de outros caminhos. Portanto, diante da fragilidade em relação a adesão dos parceiros, sugere-se: preparar a equipe para acolher o público masculino, criar horários alternativos na rotina do serviço, promover atividade educativas com os homens, dar visibilidade ao tema do cuidado paterno e fortalecer o apoio social (Brasil, 2016).

\section{Categoria 3: fatores que dificultam a realização do pré-natal do parceiro nas UBS do município de Cáceres-MT}

Conforme mencionado anteriormente, a grande maioria dos enfermeiros afirmaram que não realizam o pré-natal do parceiro. Diante desse aspecto, criou-se esta categoria para que possamos entender quais os fatores/motivos que dificultam a realização dessa estratégia.

Foi possível identificar quatro motivos principais: excesso de trabalho nas Unidades e déficit de recursos humanos, falta de informações, impedimento pelo trabalho e questão cultural: divisão de papéis homem/mulher.

\section{Excesso de trabalho nas unidades e déficit de recursos humanos}

O excesso de trabalho e recursos humanos insuficientes foram citados como fatores impeditivos para realização do pré-natal do parceiro, conforme as falas a seguir:

Acho que, talvez o excesso de demanda. Nessa unidade nós contamos com um médico e com um enfermeiro que realizam as consultas de pré-natal [...]. (Enfermeiro 1)

A gente atribui um pouquinho isso também, às vezes por falta de recursos humanos, a gente não tem uma equipe completa, a gente só tem um ACS, então assim, é muito fluxo, às vezes você até perde, teria que fazer assim um trabalho de formiguinha, intensivo mesmo, de orientação, entendeu? [...]. (Enfermeiro 3)

A estrutura física, recursos humanos e materiais, o excesso de demanda relacionada ao dimensionamento de pessoal e a falta de educação continuada são alguns motivos que provocam insatisfação nos profissionais que atuam na atenção básica e que podem comprometer a qualidade da assistência prestada (Forte \& Pires, 2017).

Para tanto, boas condições de infraestrutura, adequado dimensionamento de pessoal e agenda de trabalho que dê conta da demanda, acesso a insumos necessários são condições essenciais para garantir a humanização e qualidade de assistência, bem como, contribuir para melhor satisfação dos profissionais que ali atuam. 


\section{Falta de informações}

Alguns enfermeiros citaram como motivo a falta de informações devido não terem recebido capacitação sobre o tema:

Não, não realizo. Exatamente por não saber, exatamente por isso. Assim, as vezes o parceiro vem junto na consulta, mas é bem difícil. Então, aqui a gente não aderiu esse pré-natal do parceiro, mas seria bem importante com certeza. (Enfermeiro 9)

Não, não realizo. Eu, creio que seja por falta de informaçães. Porque assim, a gente ainda não chegou a ter alguma capacitação em relação a isso. (Enfermeiro 11)

O Ministério da Saúde produziu um material orientativo para os profissionais da saúde sobre o pré-natal do parceiro e todas as ações/procedimentos que devem ser realizados. Contudo, não se descarta a relevância da capacitação para os profissionais, pois se trata de uma temática nova e que provavelmente não foi abordada durante a formação acadêmica destes profissionais.

As capacitações dos trabalhadores de saúde na atenção básica devem ser contextualizadas na realidade do trabalho em saúde e contempladas numa política de valorização ao trabalhador. A educação permanente abrange estes aspectos, podendo ser uma estratégia de transformação da educação em serviço (Brasil, 2014).

\section{Falta de adesão do parceiro em virtude do horário de trabalho}

Alguns enfermeiros mencionaram que os parceiros não comparecem às consultas devido o trabalho que coincide com o horário de funcionamento da UBS.

A maioria deles [os homens] no horário das consultas que é horário comercial, eles estão trabalhando, então fica difícil [...] (Enfermeiro 7)

Não é porque ele [o homem] não queira vir, é porque ele trabalha [...]. (Enfermeiro 2)

\section{Muitos dão desculpa também do trabalho, fala do trabalho [...]. (Enfermeiro 6)}

Os depoimentos dos enfermeiros corroboram com outros estudos sobre o tema, pois uma pesquisa realizada com companheiros de gestantes, no município de Recife/PE, identificou que 53,8\% dos homens citaram como motivo para a não participação nas consultas de pré-natal, o trabalho (Oliveira et al., 2000). Outros estudos também identificaram que a ausência do homem nas consultas se dá pela falta de tempo devido ao trabalho (Lamy et al., 2012) e que os que participaram das consultas, na sua maioria, tratava-se de homens que estavam desempregados (Almeida et al., 2020)

Isso pode ser explicado pelo fato de que por muito tempo a importância do pai no desenvolvimento da criança foi desconsiderada em prol do relacionamento mãe/filho, pois até meados da década de 70 , as funções do pai estavam relacionadas ao provimento e sustento econômico da família. Durante a gestação a presença do pai era praticamente invisível, dava-se importância apenas às questões relacionadas à saúde da gestante e do bebê (Arpini, Cúnico \& Alves, 2016).

Nos últimos tempos tem ocorrido mudanças culturais no que se refere aos papéis da mãe e do pai, a mulher tem ganhado espaço no mercado de trabalho e o homem não é mais o único provedor, podendo este desenvolver a paternidade ativa, entretanto a cultura patriarcal ainda se faz presente na nossa sociedade (Arpini, Cúnico \& Alves, 2016).

Outro fator que pode influenciar na escolha do parceiro pelo trabalho em detrimento a participação nas consultas de pré-natal, é o desconhecimento do seu direito. Um estudo evidenciou, através das narrativas das gestantes entrevistadas, que elas não possuíam conhecimento a respeito do direito de participação de seus parceiros nas consultas de pré-natal (Costa \& 
Taquette, 2017). Portanto, apesar da existência de políticas públicas e normativas que preconizam essa participação, ainda se mostram ineficazes; falta divulgação e incentivo dessa estratégia pelos profissionais de saúde, por meio de uma postura acolhedora e de valorização do homem (Pinto et al., 2018; Cortez et al., 2016).

\section{Questão cultural: divisão de papéis homem/mulher}

O fator cultural também foi mencionado como um dos motivos que dificulta a realização do pré-natal do parceiro, pois ainda há uma desigualdade referente ao cuidado e ao papel assumido pelo homem e a mulher, conforme demonstrado nas falas abaixo:

Porque a gente ainda tem uma coisa social, que parece que a gestação é uma coisa, que o conhecimento ele é exclusivo do feminino. (Enfermeiro 1)

Simplesmente a mulher que faz tudo, homem só trabalha, coloca as coisas em casa e pronto, é assim que funciona. (Enfermeiro 9)

Eles [os homens] acham que isso [pré-natal] é coisa de mulher. (Enfermeiro 7)

As vezes ela pensa que é só ela, ela é responsável, o filho é dela, e o homem está ali para ajudar, mas não, o homem é o pai, o parceiro é o pai, precisa estar ali atuante, entendeu? (Enfermeiro 7)

Muitos homens não dão aquela importância, talvez um pouco pelo machismo, talvez cultura. Acha assim que: Ah não! Posto de saúde é coisa de mulher, eu sou machão. Cultura mesmo. (Enfermeiro 3)

De acordo com o enfermeiro 7, alguns homens ainda acreditam que o pré-natal é "coisa de mulher", isso pode ser explicado pelo fato de que no estereótipo da sociedade o cuidado é restrito ao sexo feminino. Desde a infância, através das brincadeiras de "casinha", a mulher assume o papel de cuidadora/do lar e isso reflete na forma como os casais encaram a gestação, conforme a percepção dos enfermeiros.

Essa cultura das diferenças de gênero e da divisão de tarefas entre os sexos sempre esteve presente na sociedade e os papéis assumidos por pais e mães eram tradicionalmente distintos, a mãe possuía o papel de cuidadora e o pai de provedor das necessidades materiais da família (Sousa \& Guedes, 2016).

Almeida et al., (2020) contribuem nesse sentido, ao evidenciarem em estudo semelhante, que na atualidade a sociedade ainda está ligada a questões culturais e divisões baseadas no gênero, caracterizando uma barreira para o bom andamento do pré-natal. Acrescentam a importância de que os profissionais criem estratégias afim de dar novo sentido a paternidade e estimule a participação do homem nesse espaço.

O Ministério da Saúde afirma que é compreensível essas questões culturais e de gênero, pois ainda temos uma sociedade predominantemente machista que defende a manutenção de papéis rígidos de gênero para mulheres e homens.

Outro fator é a necessidade de negação em relação aquilo que possa ser interpretado como "feminino", o que acaba afastando o homem do afeto e cuidado com os filhos e até mesmo do cuidado com sua saúde, portanto, com base nesses estereótipos, é possível compreender não apenas o distanciamento do homem em relação à gestação, mas também a exposição a situações de risco e a procura tardia pelo serviço de saúde (Brasil, 2016).

\section{Categoria 4: fragilidades do cuidado à saúde do homem}

Ao final da entrevista foi solicitado aos enfermeiros a falarem sobre a relevância do tema, de forma livre. Além de todas as questões já mencionadas, emergiu na fala dos entrevistados, aspectos relacionados à saúde do homem, sua aproximação com a Unidade e a adesão aos serviços de saúde. 
A saúde do homem é algo que precisa ser trabalhado na Atenção Básica de uma forma geral, pois as falas dos enfermeiros demonstram que tanto a realização do pré-natal do parceiro como outras ações voltadas a esse público ainda acontecem de forma fragmentada:

O que a gente vê na verdade, é que não é só o parceiro que às vezes não participa desse momento, mas o homem no geral ele não está presente dentro da unidade de saúde. Parece que o homem, ele não vê muita importância em está fazendo uma consulta de rotina. Muitas vezes ele só procura a unidade de saúde quando realmente ele está com uma queixa. (Enfermeiro 1)

A gente vê muita dificuldade nos homens, aceitação dos homens, você vê nos mutirões que a gente faz, nas campanhas, nas rodas de conversa, a procura é bem mínima do homem ainda. Eu acho que foi alguns anos atrás, acho que foi 2012, 2013, colocaram a saúde do homem, fizeram uma passeata, mas agora a gente se esqueceu, a gente não se vê mais isso, falando sobre a saúde do homem. A procura maior na unidade ainda é da mulher. (Enfermeiro 3)

Então eu acho que poderia ter um trabalho grande em relação a isso. Um trabalho que envolva agente comunitário de saúde, palestras. O povo não gosta de palestras, mas tem que ser feito, para conscientizar, para sensibilizar essas pessoas em relação a isso, envolvendo empresas privadas que têm grande número de homens, construção civil, essas coisas têm grande número de homens, para trazerem para cá, para todas as unidades de saúde esses homens, para ser conscientizado, entendeu? (Enfermeiro 7)

As falas dos enfermeiros corroboram com o cenário atual em relação aos cuidados à saúde do público masculino, pois outros estudos identificaram, também, que os profissionais encontram dificuldades para inserir o homem na AB. Essas dificuldades estão relacionadas principalmente a falta de capacitação dos próprios profissionais sobre a saúde do homem e a Política Nacional de Atenção Integral à saúde do Homem (PNAISH), a feminilização dos serviços de saúde, ao déficit de comportamento de autocuidado e incompatibilidade de horários (Moreira, Fontes \& Barboza, 2014).

Oliveira et al, (2021, pg.12) corroboram com esta ideia, ao apresentarem resultado de pesquisa de uma revisão integrativa onde buscaram "conhecer a produção científica sobre as ações de cuidado à saúde e promoção à paternidade para homens-pais durante o período pré-natal, em âmbito nacional e internacional", e acrescentaram para além das fragilidades apontadas acima, a "pouca presença do homem nos serviços de saúde, mas quando estes estão no serviço, são majoritariamente envolvidos nas ações de planejamento reprodutivo" "na obtenção de métodos contraceptivos, mas não tem uma continuidade na integralidade de sua saúde"." Notando-se uma não articulação entre ações de planejamento reprodutivo e pré-natal do parceiro e vice e versa."

O enfermeiro 3 evidencia que as ações sobre a saúde do homem são quase inexistentes e que a busca pela unidade é da população do sexo feminino, corroborando com a ideia de feminilização do serviço (Moreira, Fontes \& Barboza, 2014).

Frente a esta dificuldade de sensibilização dos homens em relação ao cuidado em saúde, o Ministério da Saúde em conjunto com as esferas estaduais e municipais que compõem o SUS, tem desenvolvido, nos últimos anos, várias campanhas e políticas, justamente por reconhecer que é preciso desenvolver cuidados específicos à saúde do homem, pois até então as políticas eram voltadas às mulheres, crianças, adolescentes e idosos. No entanto, percebe-se, através das falas dos enfermeiros que apesar das iniciativas governamentais, os profissionais ainda encontram dificuldades para trabalhar com esse público. 
Dessa forma, a estratégia do pré-natal do parceiro pode ser uma grande oportunidade para os profissionais começarem a inserir, aos poucos, o homem nos serviços de saúde, estabelecendo vínculo e adesão às ações/procedimentos e orientações.

\section{Considerações Finais}

A partir das entrevistas com os enfermeiros foi possível constatar que a realização do pré-natal do parceiro ainda é uma estratégia pouco consolidada nos serviços de saúde do município de Cáceres-MT. Identificou-se que menos da metade dos profissionais entrevistados realizam o pré-natal do parceiro, e quando realizam não desenvolvem todas as ações conforme preconizado pelo Ministério da Saúde.

É importante ressaltar que os profissionais possuem conhecimento sobre o pré-natal do parceiro e reconhecem os benefícios dessa estratégia para o trinômio mãe-pai-filho, entretanto encontram dificuldades para efetivá-la.

A saúde do homem ainda é pouco abordada, pois tradicionalmente, as Unidades de saúde dão prioridade a crianças e mulheres, até mesmo pelo fato de que os homens, de forma geral, não são adeptos as ações de prevenção e promoção à saúde e habituaram-se a evitar o contato com os serviços. Como reconhecido pelos entrevistados, os profissionais acabam "esquecendo" essa população, as ações e campanhas são voltadas para outros públicos.

Frente a estes aspectos, evidencia-se que ainda há inúmeros desafios a serem superados, e esta pesquisa traz importantes contribuições neste sentido, levantando discussões para se repensar as ações e práticas direcionadas a Saúde do Homem, dentre elas a necessidade de fortalecer a educação permanente para os profissionais da Atenção Básica, a organização da agenda da UBS com flexibilização dos horários de atendimento, o desenvolvimento de projetos e campanhas e a realização de novos estudos, possibilitando troca de saberes e aprofundamento sobre o assunto na tentativa de obter soluções para melhor envolvimento e sensibilização dos homens sobre a importância de acompanhar a mulher durante o pré-natal e os cuidados com a própria saúde.

Percebe-se que há grandes avanços em termos de políticas e campanhas voltadas à participação do pai/parceiro nas consultas de pré-natal e a saúde do homem, porém ainda há a necessidade de sensibilização e esforços por parte dos gestores e profissionais da saúde para consolidação dessas iniciativas governamentais.

Os resultados apresentados demonstram a necessidade de se avançar em estudos que busquem a compreensão das dificuldades da realização do pré-natal dos parceiros por enfermeiros bem como as barreiras que impedem a adesão dos homens aos serviços de saúde da atenção primária, a eles ofertados, no sentido de encontrar alternativas que melhorem este cenário e que indiquem as melhores ações a serem realizadas.

\section{Referências}

Almeida, D. F. de, Licar, J. M. D., Machado, L. M., et al. (2021). Manual do pré-natal do parceiro. Uniceuma.

Almeida, D. C. S., Donaduzzi, D. S. da S., Fettermann, F. A., Cortes, L. F., \& Sehnem, G. D. (2020). Potentialities and weaknesses related to the participation of the father/partner in prenatal care in the perception of nurses. Research, Society and Development, 9(8), e183985434. https://doi.org/10.33448/rsdv9i8.5434

Arpini, D. M., Cúnico, S. D., \& Alves, A. P. (2016). Paternidade: o ponto de vista de profissionais que atuam em varas de família. Pensando familias, 20(1), 29-42.

Benczik, E. B. P. (2011). A importância da figura paterna para o desenvolvimento infantil. Revista Psicopedagogia, 28(85), 67-75. http://pepsic.bvsalud.org/scielo.php?script=sci_arttext\&pid=S0103-84862011000100007\&lng=pt\&tlng=p

Braide, A. S. G., Brilhante, A. V., Arruda, C. N. D., Mendonça, F. A. D. C., Caldas, J. M. P., Nations, M. K., \& Amorin, R. F. D. (2019). Sou homem e pai $\operatorname{sim}$ ! (Re) construindo a identidade masculina a partir da participação no parto. Revista Panamericana de Salud Pública, 42 , e190.

Brasil (1986). Decreto ${ }^{\circ}$ 94.406, de 08 de junho de 1987. Regulamenta a Lei ${ }^{\circ} 7.498$, de 25 de junho de 1986, que dispõe sobre o exercício da Enfermagem, e dá outras providências. http://www.portalcofen.gov.br/sitenovo/node/4173 
Brasil. Ministério da Saúde (2009). Política Nacional de Atenção Integral à Saúde do Homem: princípios e diretrizes. bvsms.saude.gov.br/bvs/publicacoes/politica_nacional_atencao_homem.pdf

Brasil. Ministério da Saúde (2014). Educação permanente em saúde. http://bvsms.saude.gov.br/bvs/folder/educacao_permanente_saude.pdf

Brasil. Ministério da Saúde (2012). Atenção ao pré-natal de baixo risco. bvsms.saude.gov.br/bvs/publicacoes/cadernos_atencao_basica_32_prenatal.pdf

Brasil. Ministério da Saúde (2016). Guia do Pré-Natal do Parceiro Para Profissionais da Saúde. https://portalarquivos2.saude.gov.br/images/pdf/2016/agosto/11/guia_PreNatal.pdf

Brasil. Ministério da Saúde (2020). Política Nacional de Educação Permanente em Saúde. https://bvsms.saude.gov.br/bvs/publicacoes/politica_nacional_educacao_permanente_saude_fortalecimento.pdf

Caldeira, L. A., Ayres, L. F. A., Oliveira, L. V. A., Henriques, B. D. A visão das gestantes acerca da participação do homem no processo gestacional 2017;7:e1417. https://doi.org/10.19175/recom.v7i0.1417

Cardoso, V. E. P. S., Silva Junior, A. J. D., Bonatti, A. F., Santos, G. W. S. D., \& Ribeiro, T. A. N. (2018). A participação do parceiro na rotina pré-natal sob a perspectiva da mulher gestante. Rev. pesqui. cuid. fundam. (Online), 856-862.

Cavalcanti, T. R. L., \& Holanda, V. R. D. (2019). Participação paterna no ciclo gravídico-puerperal e seus efeitos sob a saúde da mulher. Enferm. foco (Brasília), 93-98.

Climaco, L. C. C., Vilela, A. B. A., Boery, E. N., \& Yarid, S. D. (2020). Pré-natal masculino: um relato de experiência no contexto da educação em saúde. Enferm. Foco (Brasilia), 11(2), 198-203.

Cofen (2017). Consulta Pré-Natal do Parceiro é incluida nos precedimentos do SUS. http://www.cofen.gov.br/consulta-pre-natal-do-parceiro-e-incluida-nosprecedimentos-do-sus_55712.html

Cortez, M. B., Machado, N. M., Trindade, Z. A., \& Souza, L. G. S. (2016). Profissionais de saúde e o (não) atendimento ao homem-pai: análise em representações sociais. Psicologia em Estudo, 21(1), 53-63.

Costa, S. F. D., \& Taquette, S. R. (2017). Atenção à gestante adolescente na rede SUS-o acolhimento do parceiro no pré-natal. Rev. enferm. UFPE on line, 2067-2074.

Fonseca Pinto, K. R. T., Martins, J. R., Campana, M. C., Quintamilha, T. D. F., Zani, A. V., \& Bernardy, C. C. F. (2018). Dificuldades na amamentação: sentimentos e percepções paternas. Journal of Nursing and Health, 8(1).

Forte, E.C.N., \& de Pires, D.E.P. (2017). Enfermeiras na atenção básica: entre a satisfação e a insatisfação no trabalho. Trabalho, Educação e Saúde, 15(3), 709-724. https://doi.org/10.1590/1981-7746-sol00083

Ganga, GM D.; Soma, TS e Hoh, GD (2012). Trabalho de conclusão de curso (TCC) em engenharia de produção. Atlas.

Gonçalves Camacho, K., Muniz da Costa, O.V., \& Progianti, J.M., \& Spíndola, Thelma (2010). Vivenciando repercussões e transformações de uma gestação: perspectivas de gestantes. Ciencia y Enfermería, XVI (2), 115-125. https://www.redalyc.org/articulo.oa?id=370441805012

Holanda, S. M., Castro, R. C. M. B., Aquin, P. D. S., Pinheiro, A. K. B., Lopes, L. G., \& Martins, E. S. (2018). Influência da participação do companheiro no pré-natal: satisfação de primíparas quanto ao apoio no parto. Texto \& Contexto-Enfermagem, 27(2).

Lamy, Z. C., Rocha, L. J. L. F., de Lima, J. R., \& da Silva, E. L. C. (2013). Paternidade em tempos de mudança: uma breve revisão da literatura/fatherhood in times of change: a brief review of the literature. Revista de Pesquisa em Saúde, 13(2).

Lima, V. K. D. S., Hollanda, G. S. E. D., Oliveira, B. M. M. D., Oliveira, I. G. D., Santos, L. V. F. D., \& Carvalho, C. M. D. L. (2019). Educação em saúde para gestantes: a busca pelo empoderamento materno no ciclo gravídico-puerperal. Rev. pesqui. cuid. fundam. (Online), 968-975.

Matos, M.G, Magalhães, A.S., Féres-Carneiro, T. T., Machado, R.N. (2017). Construindo o Vínculo Pai-Bebê: A Experiência dos Pais. Psico-USF, 22 (2), 261-271. https://doi.org/10.1590/1413-82712017220206

Mendes, S., \& Santos, K. C. (2019). Pré-natal masculino: a importância da participação do pai nas consultas de pré-natal. Enciclopédia Biosfera, 16(29).

Minayo. M.CS, Gomes, SFDR (2013). Pesquisa social teoria, método e criatividade.

Moreira, R.L S. F., Fontes, Wilma Dias de, \& Barboza, T. M. (2014). Dificuldades de inserção do homem na atenção básica a saúde: a fala dos enfermeiros. Escola Anna Nery, 18(4), 615-621. https://doi.org/10.5935/1414-8145.20140087

Oliveira, B. C. L. de., Araújo, A. D. F. de., Maciel, M. R., Klayn, B. P. S. da S., Ribeiro, C. R., \& Lemos, A. (2021). Health actions for men-fathers and promotion of fatherhood in prenatal care: Integrative review. Research, Society and Development, 10(4), e59310414460. https://doi.org/10.33448/rsdv10i4.14460

Oliveira, S. C., Ferreira, J. G., da Silva, P. M. P., Ferreira, J. M., de Almeida Seabra, R., \& Fernando, V. C. N. (2009). A participação do homem/pai no acompanhamento da assistência pré-natal. Cogitare Enfermagem, 14(1), 73-78.

Santana, L. A., \& da Silva Gonçalves, B. D. (2020). A participação do parceiro na rotina pré-natal da mulher gestante: estudo em uma unidade básica de saúde. Humanidades e tecnologia (FINOM), 20(1), 312-327.

Silva, W. C., Wanderley, R. R., Markus, G. W. S., Pereira, R. A., do Couto, G. B. F., \& Dias, A. K. (2020). Pré-natal do parceiro: desafios para o enfermeiro. Revista Extensão, 4(2), 127-137. 
Research, Society and Development, v. 10, n. 6, e43110615872, 2021

(CC BY 4.0) | ISSN 2525-3409 | DOI: http://dx.doi.org/10.33448/rsd-v10i6.15872

Sousa, L. P. D., \& Guedes, D. R. (2016). A desigual divisão sexual do trabalho: um olhar sobre a última década. Estudos avançados, 30(87), 123-139.

Sousa, S. C. de., Oliveira, F. B. M. de, Sousa, F. das C. A., Silva, S. S., Silva, W. C. da ., Lima, K. L. A., Mendes, R. C. ., Hernandes, L. F., Miranda, L. S. C., \& Silva, R. A. da . (2021). Prenatal assistance: father's participation in healthy pregnancy. Research, Society and Development, 10(1), e14710111330. https://doi.org/10.33448/rsd-v10i1.11330 